\title{
9 \\ Aspirations of Home Making in the Nursing Home
}

Natashe Lemos Dekker and Jeannette Pols

The vision statement of the De Klaverhof nursing home in the Netherlands reads: 'Our aim is that residents and their family members experience this house as their home.' In the document as well as on its website, De Klaverhof emphasizes the importance of creating a 'homely' living space for its residents, paying specific attention to the needs of people with dementia. Enabling nursing home residents to feel at home is widely considered important. It is also recognized as a challenge that requires reflection and policy and design interventions (Van Hoof and Wouters 2014; Van Hoof et al. 2015; Shield et al. 2014). Levy et al. (2019) describe the nursing home as 'a unique, hybrid space in which state interests and intimate activities are closely entwined' (328). As the nursing home is a place for living, working, caring and visiting, it has multiple aims (Chatterji 2006; Davies 2017; Haeusermann 2018; Innes 2009) and balances between public and private realms, between the institution and home.

\footnotetext{
N. Lemos Dekker $(\bowtie) \bullet$ J. Pols

University of Amsterdam, Amsterdam, The Netherlands e-mail: N.LemosDekker@uva.nl; a.j.pols@uva.nl 
Feminist scholars have alerted us to not assume stable boundaries between the public and the private (e.g. Scott and Keates 2004). Challenging traditional designations of the private and the public, they have shown instead the intertwinement of the political with the most intimate realms of life and vice versa. This becomes particularly important in the nursing home as the public institution merges with the privacy of home. In this chapter, we show how aspirations of creating home in the nursing home produce a continuous negotiation between public and private space, between 'feeling at home' and professional care, and between objects and routines feeling homely or institutional. The boundaries between these fade in unexpected ways and are enforced in others. How does the aspiration of 'being a home' intervene in relating the private and homely on the one hand and the public and institutional on the other?

\section{Fieldwork}

Our discussion is based on the analysis of policy documents and on eighteen months of ethnographic fieldwork conducted by Natashe in nursing homes in the Netherlands. Through participant observation, she took part in daily life in the nursing home and held interviews and informal conversations with professionals (including care staff, physicians and management), family members and, when possible, people with dementia. We will dwell specifically on observations and conversations in a particular nursing home we refer to as De Klaverhof. We also analysed documents De Klaverhof has published about its policy of home making. While some of the characteristics we describe are specific to De Klaverhof and its design and organization, the tensions we address between home and institution resonate with attempts to create home in the institution in long-term care facilities elsewhere in the Netherlands and in other Western countries.

\section{Theoretical Background}

De Klaverhof, like many other nursing homes in the Netherlands, aspires to make the nursing home as homely as possible, and these aspirations always resonate with cultural norms and values (Appadurai 2013). The turn 
towards creating a home in Dutch nursing homes can be seen as a move away from the 'total institution', which Goffman (1961) defines as a place of 'residence and work where a large number of like-situated individuals, cut off from the wider society for an appreciable period of time, together lead an enclosed, formally administered round of life' (xii). While the total institution can refer to a range of settings, including prisons and mental asylums, Goffman also recognizes its characteristics in care institutions for the elderly. These characteristics include, among others, a setting where a single authority dictates the rhythms of life for a large group of people, where physical barriers often separate the inside and outside, and where the separation between work, sleep and play collapses. Arguably, the nursing home is a setting that resembles many of these characteristics. Accordingly, it has been framed as a place where autonomy, privacy and dignity are threatened (Buch 2018; Leibing et al. 2016; Van Wijngaarden et al. 2015). The proliferation of such negative imaginaries of the nursing home is connected to this totalizing character of the institution.

Bringing the home into the institution can be challenging given the differential organization of both. For Mary Douglas (1991), the home constitutes a place where control can be exercised. Understanding home in this way sensitizes us to issues of control and access. Where Douglas considers the home to be a kind of space, others have drawn attention to the home as a feeling and a sense of belonging (e.g. Duyvendak 2011), as well as a mode of action (e.g. Visser 2017,2019). Renske Visser speaks of 'doing home', making explicit that the home is not static or fixed in space, but is a process in which home is actively created. To understand the integration of home and nursing home, then, it is important to take into account this processual character of home and the practices that substantiate or challenge it.

In our approach to home we do not pre-define what home comes to mean, but take these sensitivities with us. First, we analyse policy documents to see the aspired-to notions of home. Then, we move on to nursing home policy, where home is linked to meeting residents' personal needs. Finally, we observe how home and institution emerge in the space of the nursing home, with its delineations of personal and professional space, the type of objects that are attributed to homeliness or professionality and the routines belonging to each. 
To contextualize the relationships between home and institution, we will now turn to policies both at De Klaverhof and at the national level. These policies provide particular framing for the aspiration of home in the institution in relation to a particular set of values: safety, familiarity, autonomy and privacy.

\section{Aspirations of Home in National Policy}

At the national level, the effort to make nursing homes more homely paradoxically coincides with state policy that has been seeking to reduce the number of people being admitted to nursing homes by encouraging them to remain at home longer, also known as the 'ageing-in-place' paradigm (Morley 2012). This is a spatial understanding of home where home is the house that people lived in before the need to move to an institution. As a result of this policy, the average time people with dementia live in a nursing home decreased from 485 days in 2013 to 430 days in 2015 (ActiZ 2015).

Through enforcing this spatial separation, people move into the nursing home with increasingly severe care needs, making their residence shorter but also more intensive (Van Hoof and Wouters 2014). The national 'Longer at Home' policy (VWS 2018a) is justified as responding to the wish of elderly people to stay at home, which it explicitly associates with autonomy, but which also reflects the negative image of nursing homes. Nursing homes are associated with rising costs of care in an ageing society (the number of people aged 75 years and older is expected to double from 2020 to 2040; VWS 2018a) and are framed as places elderly people do not want to go. Moving to a nursing home is seen as separating them from their homely environment and as jeopardizing their autonomy and quality of life. Against the backdrop of such negative imaginaries of the nursing home and the ideal of the home where autonomy is possible, the home is framed as the ideal place to spend the final stages of life as well as the preferred place of death (De Veer and Kerkstra 2001; Visser 2019; see also Jacobsen, Chap. 5, this volume).

Notwithstanding the new policy, however, people with dementia in the Netherlands usually move to a nursing home as the disease progresses. This common practice of institutionalization at the end of life means 
that, according to a study from 2003 , over $90 \%$ of people with dementia eventually die in a nursing home (Houttekier et al. 2010: 753), with the number of elderly people in nursing homes increasing (VWS 2018a). Dementia is the primary cause of death in the Netherlands, with 15,400 deaths recorded in 2016 (CBS 2017). ${ }^{1}$ These statistics indicate that most people with dementia in the Netherlands die in a nursing home setting and live a significant amount of time in the institution before their eventual death. The nursing home is thus an important setting in which political and moral imaginaries about home and institution take shape.

The discrepancy between the negative image of the nursing home and the idealization of home as the best place to die formed a challenge for Dutch health-care policies. There were many complaints about the quality of care in nursing homes. Simultaneously, a complete turn to ageing-in-place remained unrealistic, as the figures given testify. For this reason, the government decided to invest 2.5 billion euros to improve care in nursing homes. How could the quality and the image of nursing homes be improved? Interestingly, notions of 'home' took central stage in national quality frameworks for nursing homes (VWS 2018b). The concepts of 'quality' and 'home' became almost synonymous; nursing home care improves if nursing homes become more like a home. Hence, attempts are made to create a more homely environment for nursing home residents and nursing homes like De Klaverhof are actively involved in constructing practices they see as home making.

\section{Aspirations of Home in Nursing Homes}

How do nursing homes aim to create a home in the institution? A number of international studies has focused on home-making practices in nursing homes, and a range of interventions has been created and proposed (Lovatt 2018; Van Hoof et al. 2015, 2016). One set of interventions is focused on making the material environment more homely. Administrators, for example, attempt to create a more homely environment through physical

\footnotetext{
${ }^{1}$ These numbers have also been subject to critique. On the one hand, the end of life with dementia often involves comorbidity, challenging the possibility to ascribe a death to one condition or other. On the other hand, dementia was the biggest category as an umbrella term for various diseases, including Alzheimer's, while different forms of cancer were listed separately. Had the latter been grouped, then cancer would have been the primary cause of death (CBS 2017; De Volkskrant 2017).
} 
enhancements and by (re)designing the material environment (Shield et al. 2014; Van Hoof et al. 2015; De Veer and Kerkstra 2001). Efforts that address the physical environment are accompanied by a second set of interventions to create homeliness through professionals' efforts. Personcentred care, being attentive to residents' needs and preferences and providing meaningful activities are seen as central to the social environment that constitutes a home (De Veer and Kerkstra 2001; Kamphof and Hendriks, this volume; Van Hoof and Wouters 2014; Van Hoof et al. 2015). Professionals are thus requested to provide an environment of individual attention.

What has resulted is an effort to make residents feel as homely as possible within the nursing home. To do this, the nursing home provides residents with a familiar and recognizable setting where they feel safe and respected, can enjoy their privacy and can live according to personal preferences. Paradoxically then, and fundamental to the institutional aspiration of providing a home, is the idea that homemaking could be done anywhere, and is not confined to people's houses' (Visser 2019: 7). The link between home and the space of a private house that was made in policy is loosened. No longer is being at home in an institution a contradiction in terms (Wahl, in Van Hoof et al. 2015: 8).

Still, the ageing-in-place policy holds its force. This implies that people move to nursing homes only when they become dependent on intensive caregiving and can no longer live safely in their own homes. The central values of safety, familiarity, autonomy and privacy, as ascribed to the home setting, are precisely what is at risk when institutional care is needed, even more so in the context of progressing dementia. The phrasing 'as homely as possible', formulated in De Klaverhof's vision statement and often expressed in conversations, reveals the ambition of home making, but also contains the recognition of its limits. This objective apparently cannot be fully achieved or requires ongoing effort in a setting that is inevitably both professional and private, institution and home. How does De Klaverhof work with the tensions between public and private, between the institution and the home, in its professional homemaking efforts? 


\section{De Klaverhof Nursing Home: A Public-Private Place}

De Klaverhof tries to integrate home and institution through the use of designated spaces. This proves to be difficult and ambiguous. As is common in the Netherlands, the psychogeriatric ward of De Klaverhof is divided into units of small-scale living that are referred to as woningen, which translates in this context closest to 'residences'. Each of these fourteen units houses six residents, each of whom has their own private bedroom. Toilet facilities and a living room with an open-plan kitchen are shared. As the nursing home stresses in its policy documents, the layout of the nursing home has been oriented towards the idea of a household. In this way, the abstract values of home are operationalized as relating to a use of space that signifies well-being: 'Surroundings, interior, and freedom of movement have psychological and physical effects on people', the vision statement asserts. Freedom of movement is deemed important for a sense of home. Residents can move between the different units in the ward through wide corridors with large windows that look out onto the courtyard. Along the way, they will pass through the café, beside various benches and past the entrances to different units.

However, this freedom of movement has limits. The ward is closed and can only be exited using a four-digit code. It is located on the second floor, and there is no direct access to the courtyard. There is a small cafe inside the ward where daily activities are also organized. Furthermore, De Klaverhof has in-house elderly-care physicians, a physiotherapist, ergotherapist, psychologist, social worker and chaplain, as well as a restaurant, hairdresser, manicurist and a small shop, which residents can visit when accompanied. 'Home' here is imagined as embedded in a community where all these facilities may be part of everyday life, but they may be ambiguously inside or outside the home, accessible or not.

Aspiration to create a home-like environment also involves taking a more person-centred approach, which means that the framework of the institution is altered in favour of individual needs and preferences. This reflects a shift in focus towards enabling autonomy and privacy. Smaller units and private bedrooms contribute to this and emphasize the 
nursing home as a living space. These are changes that should counteract the institutional character of the nursing home (Shield et al. 2014).

Still, it is to a large extent the institution that dictates what forms this private sphere within its walls can take. Some elements characteristic of the institutional setting remain in place, such as the closed ward and bureaucratic systems and rules. Hence, as we will illustrate next, in its aspiration to create a homely as well as professionally caring environment, the nursing home reveals how its various aims - care, quality of life and treatment-are also valued differently in different situations. At times, these aims can be contradictory and produce tensions and ambiguities, can merge and strengthen each other or can develop in unforeseen ways.

\section{Access and Control in Private and Shared Spaces}

Important in the use of spaces to negotiate home and institution are authorizations over who has access to and control over each space. We saw that, from the open corridors, the shared living rooms and the private bedroom, the ward distinguishes various layers of public and private. In the private bedroom, familiarity is created through personal objects, and autonomy is emphasized through the possibility of accessing this space at will and exercising control over what happens in it.

All residents of De Klaverhof have a private bedroom. Generally, shared rooms in nursing homes have become highly exceptional in the Netherlands, following critique in the 1990s on the hospitalizing environment of the nursing home (Van Hoof and Wouters 2014; De Veer and Kerkstra 2001). As a space that residents, together with family, could decorate according to their own preferences, they allowed for the creation of a familiar environment through personal objects. In De Klaverhof, the rooms are furnished with standardized, basic furniture. Each room is equipped with a bed on wheels that can be lifted and tilted to support the residents and that lives up to professional standards for caregivers to facilitate getting residents in and out of bed. The rooms also come with a wardrobe and a sink. Additionally, residents can bring their own personal 
items and small furniture, and the decoration of the room is, to a large extent, dependent on the efforts of family members.

Quite often, residents had brought a cabinet and pictures of family or paintings that used to hang on the wall in their previous homes. Generally, they would have objects that were meaningful to them or that said something about the resident's life. Mr Schuurman, for example, had a large antique radio in his room. When asked about it, he proudly started talking about his electronics store. Similarly, Mrs Smit had a glass display cabinet with flower arrangements made of beads. Her daughter clarified: 'My mother has always been a creative woman. She made all these herself.' Mrs Smit remained surrounded by things that had always brought her pleasure. The personalization of the private room through personal belongings is commonly praised as beneficial for a sense of home. Personal belongings can provide points of recognition and are seen as a source of familiarity (Van Hoof et al. 2015; Van Hoof and Wouters 2014). In this way, home making in the nursing home is also about creating familiarity through personal belongings and through a continuum in the life narrative of the resident.

However, this does not always work out as expected, as people's experiences can change. On the floor next to the cabinet stood some of Mrs Smit's paintings that had been taken down from the wall. Her daughter explained that she had started seeing men who wanted to kill her in these pictures. Although they were her own pictures, they no longer contributed to her well-being. While these changes can partly be attributed to Mrs Smit's dementia, this observation is also in line with Lovatt's (2018) argument that the meaning of personal belongings brought into the nursing home is not inherent to the object or fixed, but is created in ongoing interactions and can change over time. Personal belongings, in short, are deemed particularly meaningful in stimulating a sense of home but, as the relation to objects can change, they do not always guarantee familiarity.

The bedroom was thus most explicitly framed as a private space where the placing of objects was at the discretion of the resident or the family. The nursing home vision statement addresses this as follows: 'Residents all have their own room, with personal furniture and objects. ... This room is their private domain. No-one enters without knocking. Residents 
are allowed to mess in their room as they like. Their closet is not locked.' However, this is not the case for other spaces within the nursing home. To whom, then, does the home pertain; who has access to or authority over which parts; and when is access limited?

One afternoon, for example, Jannie was looking into the kitchen cupboards, taking out and replacing some of their contents. She was a tall woman who was often a little restless. Although taking tiny steps, she was always on the move through the unit, initially without a walker, but later with one. Upon seeing her, Lilian, one of the care workers, said, 'Jannie, stay out of that cupboard.' Jannie did not respond and continued shuffling things around. 'Jannie, get out of that cupboard, it is not yours,' Lillian said in a louder tone of voice, to which Jannie replied, 'What do you mean, it is not mine?' Lilian responded, 'That is the common cupboard.' The 'common' cupboard in this situation seems not to be that common at all: for Jannie, 'common' turned out to imply that it was not hers.

Who has access to and authority over the nursing home's various spaces thus becomes a central concern in the process of home making. While the vision of homeliness in the bedroom involves an assumption of autonomy and access, this instance shows the limitations of such idealized notions. The spaces beyond the bedroom reveal a professional rather than a homely logic, and the boundaries between the two realms were made tangible. Approaching the home as a space where control can be exerted, as Douglas (1991) has argued, was at odds with the institutional organization of space where, quite unlike home, the cupboard is not yours'. The home is brought closer by designating a space in which one is free to move, whereas other spaces remain off limits. This spatial organization creates private and public spaces and spaces 'for staff only'.

\section{(In)visibility as Home Making}

While, as just noted, some objects were categorized as private and contributing to a sense of home, others reinforced the institutional setting. The second negotiation between home and institution concerns the visibility of material objects. We observed that objects associated with the 
institution were criticized for being in sight as they were thought to obstruct the aspiration of home making. In other words, they should be there, but they should be hidden. Consider the following fieldnote:

August 4, 2015: When I arrived at De Klaverhof this afternoon and walked towards one of the units, a pleasant smell welcomed me. In the kitchen I saw Walter, who cheerfully greeted me and told me he was making soup. His mother in law, Mrs. Evertsen, was seated at the table and had various vegetables and herbs in front of her. We sat down with her and Walter started cutting the vegetables. We talked about all sorts of things, including health care policies and how he thought things were going in the nursing home. 'They should make it more liveable here' he said, and pointed to the plastic flowers in a vase on the table. 'This is too ugly. They shouldn't have such things they wouldn't want for themselves either.' Then he turned towards the medicine cart and the metal cabinet where the residents' folders were stored. 'Look at this. It makes it all so medicalized.' He continued by pointing at the bulletin-board. 'That too. It makes it so hectic, all these lists on the wall. That should not be there. This is their living room.'

Walter categorized specific objects as either 'homely' or 'clinical', placing these in binary opposition. The clinical objects challenged a sense of home and, while studies have shown that flowers can contribute to a homely atmosphere (e.g. Van Hoof et al. 2015), the fake flowers meant precisely the opposite for Walter. They were 'too ugly', signifying an inadequate effort to introduce objects that enhance the aesthetics of home, even if they are not clinical either. The plastic flowers seem to be a sign of the difficulty of home making, illustrating that residents may not have a shared taste for what home should look like (see Kamphof and Hendriks, Chap. 13, this volume, for a critical analysis of 'façades' in nursing homes).

Concern for the visibility of administrative documents was also addressed in the nursing home vision statement: 'Care staff perform their administrative tasks as much as possible in the residence. There are lockable cabinets available where privacy-sensitive documents can be stored. Announcements and lists for care staff are not put on the walls. Care staff organize the transfer in the dedicated folders.' Here, the vision statement underlines the integration of the unit as a home and a place of work. This 
means that care staff no longer kept the care records in the nurses' office and thus would not have to remove themselves from the unit. Instead, the aim was that they remained among the residents as an integral part of and overseeing the unit. Thus, care staff were encouraged to fill in care records while among residents and family members present in the living room, although the visibility of the records themselves as well as of other work-related objects was considered problematic.

This idea of integrating care staff in the homely setting of the nursing home became part of the quest for homeliness. Lisanne, the manager of the psychogeriatric ward, underlined the importance of involving staff in the upcoming refurbishment of the units so that they could indicate what they thought would be fitting for the unit, what they needed and what they liked. She enthusiastically explained that an external company with extensive experience in creating living spaces for people with dementia was going to redesign the ward. This was an important upcoming step in the creation of a more homely environment. Following the conviction that home reflects personal tastes and styles, the idea was discussed to design each unit with a different 'character'. Herein, the example was intended to follow the well-known Hogeweyk 'nursing home village', where each residence is designed according to a specific 'lifestyle': urban, upper class, cosmopolitan or traditional (Vivium Zorggroep 2019). Although it was still uncertain if this would be desirable or feasible, Lisanne stressed that this design process would in any case be undertaken together with care staff, adding: 'It should also become their house. They should also feel at home here.' She was aware of the possible tensions between the nursing home as a home and as a workspace, and sought to address this by involving care staff in the process of home making.

Such tensions about what should be visible and who should feel at home also emerged in discussions around staff uniforms. The vision statement reads: 'To underline the normalcy, staff do not wear uniforms. If needed due to hygiene requirements, appropriate clothing can be worn during nursing activities.' In practice, however, there was much debate in De Klaverhof about whether or not care staff should wear a uniform during their shifts. The uniform consisted of a white buttoned shirt with a 
pastel-coloured collar and was, at the time of our fieldwork, only worn by care staff (and not by elderly-care physicians or other disciplines). Opinions on this matter differed among care staff. Some raised concerns regarding hygiene. They saw the shirt as protection for their own clothes during nursing activities. Others were more concerned about being recognizable for residents and visitors. The uniform was thought to communicate a sense of professionality and could provide recognition of their position and identity as care staff. Finally, practical issues were raised such as where to keep loose items and belongings, including keys to the ward, their service phone and latex gloves.

Arguments against wearing a uniform offered alternative ways to address these concerns. Recognizability could be secured by wearing a name tag, and a belt with pockets or a purse could be provided for loose items. The idea was also raised to only wear the shirt during nursing activities where hygiene was at stake. 'And why does it have to be a white shirt?' Lisanne asked, making explicit the association between white shirts and clinical settings. For her, the uniform emphasized illness, 'as if people are staying in a hospital'. Rather than creating an intimate relationship with residents, she reasoned, the uniform also stood for inequality between staff and residents: 'It creates distance, precisely what we do not want. Everything should be as normal as possible, as much as possible as at home' - even professional activities.

Discussions about whether and how to keep certain objects such as uniforms and care records out of sight reflect the intertwinement of the various needs and preferences of staff and residents in creating home. The material forms for creating a home in the institution had to shift. The clinical practices of the nursing home themselves were not challenged, but they were shielded from view (or, in Walter's case, scrutinized for being in view) because they were not in line with the aspiration of being a home. Considerations about what should or should not be visible, then, become a strategy of home making, but also change the understanding of the professional task of caring, which has come to include creating a home. 


\section{Everyday Routines}

The third way of relating home and institution we observed was the integration of everyday rhythms of familiarity and efficiency. To a large extent, the familiarity that contributes to a sense of home was sought through 'homely' routines and interactions. As Duyvendak writes, 'attachment to a home is seen as ... created by familiar daily routines and regular settings for activities and interactions' (2011: 27; see also Van Hoof et al. 2015; De Veer and Kerkstra 2001; Visser 2019). Home making in De Klaverhof, then, was not just a matter of creating a homely material environment, but required attention to social interactions and rhythms. In particular, activities of preparing meals and eating together were valued in creating a sense of home. With this routine, the nursing home turned its back on the primacy of organizational efficiency that characterized the more clinical nursing homes preceding the small-scale ones. It would, for example, be more time and cost efficient to have a central kitchen for all units. Instead, a care worker would cook dinner in the open-plan kitchen in each unit, which formed an important attempt for it to be experienced less as an institution by residents and family.

Groceries were ordered online at the local supermarket and delivered weekly. Sometimes care workers would involve residents in the cooking process. One resident, for example, was often asked if she wanted to peel the potatoes, to which she eagerly agreed. In this way, the cooking not only happened in the unit, but became an activity residents could take an active part in as far as they were willing and able. The extent to which residents were involved depended also on the care worker working that day: some attached great importance to keeping residents active and engaged, while others preferred to prepare the meal by themselves. Homeliness was hence created by the quality and preparation of the food as well as in the possible participation of the residents in cooking activities.

Once dinner was ready, all residents, as far as they were physically able, sat at the table. Often residents would pick the same seats, merging their routines with those of the nursing home. Daily cooking and the familiarity of the smells and sounds of cooking activities were seen as ways to create a sense of home in each unit. Establishing cooking as part of the 
routines and rhythms of everyday life was one of the ways in which the nursing home sought to produce a homely atmosphere. Mol has addressed this, stating that 'meals are events' (2010: 217), recognizing the importance of sociability and cosiness in such moments.

Other daily routines included moments for coffee and lunch at fixed times in an attempt to create home through regularity and familiarity. How lunch should be served, however, was subject to discussion between the manager and care staff. The manager wanted the table to be set with cheese, spreads and bread in baskets so that residents could prepare their own sandwiches. On the one hand, homeliness was sought in the communal activity and routine of the shared meal. On the other hand, it was aligned with notions of autonomy: setting the table in such a way that residents could decide for themselves what they wished to eat and could prepare it themselves, instead of serving ready-made sandwiches. Care workers were sometimes hesitant about this approach and preferred to prepare lunch in the kitchen. For some residents who could not prepare their own meal, this was necessary. For those who could, sometimes with assistance, it was also a practical consideration: preparing the sandwiches in the kitchen would be quicker and cause less mess. The aspired homely experience of a shared meal was maintained, but concerns for efficiency prevailed when messiness could be prevented.

These ambiguities can appear in the smallest of gestures. On several occasions, residents who had sugar in their coffee asked: 'Where is the spoon?' 'I have already stirred it,' care workers would reply. In these instances, they had prepared coffee in the kitchen for all residents in the unit, added milk or sugar for those who wanted it, stirred all cups with a single spoon and brought them on a tray to the living room. The absence of a spoon in their coffee confused some of the residents for whom stirring their coffee was a habit. It breached their sense of familiarity with the routine of drinking coffee. In this sense, a small disruption also occurred in their routines of home. Routines such as communal meals and coffee breaks are valued as contributing to the sense of home in the nursing home. But they can also be difficult to maintain when aspirations of home as autonomy clash with efficiency and what is possible in daily practice. 


\section{Conclusion}

The nursing home is an ambiguous site that aims to reconcile both institution and home, but does not fit well in either of these (normative) categories. Individual nursing homes as well as national policies have expressed the aspiration to make the nursing home more homely following an ideal of home that is grounded in autonomy, privacy, safety and familiarity. Significant steps are being taken to bring this aspiration into practice. We have discussed three ways in which De Klaverhof addresses tensions and ambiguities between home and institution.

The first way concerned organizing access to and control over space. Access and control on the part of residents were mostly centred in the private bedroom. The shared spaces were more ambiguous; the institutional demand for order could restrict access to spaces outside the bedroom. In part, this served to protect the safety of residents, but it also maintained organizational logic. The notion of home was further extended by the idea of a household within a community, but here too, access was restricted.

The second way of relating home and institution was about aesthetics and the way professionals were visible to residents. This involved a categorization of objects as either homely or clinical. The visibility of those objects ascribed to the institution was subject to debate. Simultaneously, nursing staff were invited to become members of the household themselves.

The third way of negotiating home and institution was through creating rhythms and routines. In some ways, the aim of homeliness was well integrated into the everyday rhythms of the institution, as we observed in the preparation and consumption of meals. At times, however, concerns for organizational efficiency prevailed over the notion of home as symbolizing autonomy.

These attempts at home making show that the institutional character of the nursing home cannot be made invisible altogether: it remains a site with its own logic. The experiments with home making in De Klaverhof show that building a home is a process involving different layers that is still in progress. The integration of spheres within its walls requires ongo- 
ing reflection, debate and effort. Home is constantly in flux, and it is hard work to relate the public to the private.

As objects and routines are ascribed to the domains of home and institution, the binary between public and private takes different shapes and is under construction. We saw in De Klaverhof how staff, residents and family navigate the emerging tensions between public and private, institution and home as they move between different spaces, objects, relationships and routines. In everyday practice, they run against the limits of home within the institution, but they also create unexpected space to bring out at least some of the values of home.

To aspire to home, then, is not to place it in binary opposition to the institution, but to aspire to a well-informed integration of both home and institution that is recognizable for residents. Despite critiques of current flaws in this balance, the aspiration of home is a hopeful one: it seeks to move away from the negative imaginaries surrounding the nursing home and aims to meet the preferences of those who live and work there.

\section{References}

Appadurai, Arjun. 2013. The Future as Cultural Fact: Essays on the Global Condition. London: Verso.

ActiZ. 2015. Feiten en Cijfers Verpleeghuiszorg. https://www.actiz.nl/stream/ 160715-feiten-en-cijfers-verpleeghuiszorgdef.pdf. Accessed August 6, 2017

Buch, Elana D. 2018. Inequalities of Aging: Paradoxes of Independence in American Home Care. New York: New York University Press.

CBS. 2017. Dementie oorzaak een op de tien sterfgevallen. https://www.cbs.nl/ nl-nl/nieuws/2017/29/dementie-oorzaak-een-op-de-tien-sterfgevallen. Accessed October 16, 2019.

Chatterji, Roma. 2006. Normality and difference: Institutional classification and the constitution of subjectivity in a Dutch nursing home. In Annette Leibing and Lawrence Cohen (eds.), Thinking About Dementia: Culture, Loss, and the Anthropology of Senility. New Brunswick: Rutgers University Press.

Davies, Janette. 2017. Living Before Dying: Imagining and Remembering Home. New York: Berghahn.

De Volkskrant. 2017. Dementie is volksziekte en doodsoorzaak nummer één. Is dat echt zo? https://www.volkskrant.nl/ts-b62d5591. Accessed October 16, 2019. 
Douglas, Mary. 1991. The idea of a home: A kind of space. Social Research, 58(1): 287-307.

Duyvendak, Jan Willem. 2011. The Politics of Home: Belonging and Nostalgia in Western Europe and the United States. New York: Palgrave Macmillan.

Goffman, Erving. 1961. Essays on the Social Situation of Mental Patients and Other Inmates. New York: Anchor Books.

Haeusermann, Tobias. 2018. Professionalised intimacy: How dementia care workers navigate between domestic intimacy and institutional detachment. Sociology of Health \& Illness, 40(5): 907-923.

Houttekier, Dirk, Joachim Cohen, Johan Bilsen, Julia Addington-Hall, Bregje D. Onwuteaka-Philipsen, and Luc Deliens. 2010. Place of Death of Older Persons with Dementia. A Study in Five European Countries. Journal of the American Geriatrics Society 58: 751-756.

Van Hoof, J., M.L. Janssen, C.M.C. Heesakkers, W. van Kersbergen, L.E.J. Severijns, L.A.G. Willems, and M.E. Nieboer. 2016. The importance of personal possessions for the development of a sense of home of nursing home residents. Journal of Housing for the Elderly, 30(1): 35-51.

Van Hoof, J., M.M. Verhagen, Eveline J.M. Wouters, H.R. Marston, M.D. Rijnaard and B.M. Janssen. 2015. Picture your nursing home: Exploring the sense of home of older residents through photography. Journal of Aging Research. DOI: https://doi.org/10.1155/2015/312931.

Van Hoof, Joost and Eveline J.M. Wouters (eds.). 2014. Het Verpleeghuis van de Toekomst is (een) Thuis. Houten: Bohn Stafleu van Loghum.

Innes, Anthea. 2009. Dementia Studies: A Social Science Perspective. Los Angeles: Sage.

Leibing, Annette, Nancy Guberman and Janine Wiles. 2016. Liminal homes: Older people, loss of capacities, and the present future of living spaces. Journal of Aging Studies, 37: 10-19.

Levy, Karen, Lauren Kilgour and Clara Berridge. 2019. Regulating privacy in public/private space: The case of nursing home monitoring laws. Elder Law Journal, 26(2): 323-364.

Lovatt, Melanie. 2018. Becoming at home in residential care for older people: A material culture perspective. Sociology of Health \& Illness, 40(2): 366-378.

Mol, Annemarie. 2010. Care and its values: Good food in the nursing home. In Annemarie Mol, Ingunn Moser and Jeannette Pols (eds.), Care in Practice: On Tinkering in Clinics, Homes and Farms. Bielefeld: Transcript Verlag.

Morley, John E. 2012. Aging in place. Journal of the American Medical Directors Association, 13(6): 489-492. 
Scott, Joan W., and Debra Keates. 2004. Going Public: Feminism and the Shifting Boundaries of the Private Sphere. Urbana: University of Illinois Press.

Shield, Renée R., Denise Tyler, Michael Lepore, Jessica Looze and Susan C. Miller. 2014. "Would you do that in your home?" Making nursing homes home-like in culture change implementation. Journal of Housing for the Elderly, 28(4): 383-398.

De Veer, Anke J.E. and Ada Kerkstra. 2001. Feeling at home in nursing homes. Journal of Advanced Nursing, 35(3): 427-434.

Visser, Renske C. 2017. Unpacking Home: Ageing and Dying in Older Age in the Southwest of England. Doctoral thesis. University of Bath.

- 2019. Going beyond the dwelling: Challenging the meaning of home at the end of life. Anthropology \& Aging, 40(1): 5-10.

VWS. 2018a. Programma Langer Thuis. The Hague: Ministerie van Volksgezondheid, Welzijn en Sport.

2018b. Thuis in het Verpleeghuis: Waardigheid en Trots op Elke Locatie. The Hague: Ministerie van Volksgezondheid, Welzijn en Sport.

Van Wijngaarden, Els, Carlo Leget and Anne Goossensen. 2015. Ready to give up on life: The lived experience of elderly people who feel life is completed and no longer worth living. Social Science and Medicine, 138: 257-64.

Zorggroep, Vivium. 2019. Stads, huiselijk of Goois: Wonen in leefstijl. https:// www.vivium.nl/dementie-wonen-in-leefstijl. Accessed 9 Jun 2019. 
